\title{
The Collusion Deterrence with Prisoner's Dilemma
}

\author{
Aidong Liu, Jinfang Liu \\ Business School of Central South University, Changsha, China. \\ Email: Liujinfang79@yahoo.com.cn \\ Received September $29^{\text {th }}, 2009$; revised September $15^{\text {th }}, 2010$; accepted October $25^{\text {th }}, 2010$.
}

\begin{abstract}
I tried to present a new method to prevent collusion through employing two auditors at the same time and inspiring them provide true report by exploiting their prisoner's dilemma. But I found this method cannot be put into practice because of the high cost. So I analyzed whether sending the second auditor in a probability, a low cost method, can deter the audit collusion. I find sending the second auditor in a probability, enforcing the rigidly lawful punishment and perfecting the reward mechanism can prevent audit collusion. I also find the auditor's ethical constraint do good to prevent collusion and the charger of state assets management can play the same role as the real owner of the state-owned enterprise in deterring collusion. This finding provides theory support for the government to implement the publicly audit bidding and random double auditing system on state-owned enterprise. The supervision of PCAOB on auditors is also the operation of this theory.
\end{abstract}

Keywords: Audit Collusion, Prisoner's Dilemma, Double Auditing, Ethical Constraint

\section{Introduction}

Who polices the police? This question has troubled mechanism-designers ever since the early days of the Roman Empire. The loose supervision on auditors will induce them to collude with the auditee. Sunbeam, Cendant, Waste Management, Enron and Worldcom all involve the audit collusion [1]. Furthermore the failing to deter audit collusion leads to American subprime lending crisis to some extent. The auditors are suspected of collusion because they do not obey the professional morality to carry out the whole auditing process and fail to disclose the serious risk of the problematic company in subprime lending chain. This outstanding economic crisis strongly reveals the importance of collusion deterrence.

It's urgent to find an effective way to deter collusion. First of all, we need to analyze what caused the collusion. An important reason is the divergence between the goals of the principal and the auditor. Three kinds of problems may arise from the divergence between the goals of the principal and those of the auditor. 1) If the auditor needs to spend (unwanted) effort to find out compensation-relevant information about the agent, he may shirk and report inaccurately. 2) If the auditor and the agent can jointly manipulate compensation-relevant information and can write self-enforcing side-contracts, they may manipulate their information to play coopera- tively against the principal. 3) If the auditor can manipulate by himself, compensation-relevant information about the agent, he may frame and blackmail the agent. Baiman et al. deal with the first problem in an auditing model [2]. It seems that the third problem (framing) has yet to be studied by economists. Our paper analyzes the problem of side-contracts.

Our concern is to find a way to prevent collusion in hierarchies of self-interested agents and auditors. Baiman et al. have provided a excellent collusion-proof contracts, they only use one auditor to supervise the manager and make the auditor and manager supervise each other to secure the pursued equilibrium [3]. Finkle and Shin also give a optimal auditing policy according to the accuracy and the frequency of audits [4]. But here we would like to use a second auditor to monitor the first one. If the principal decides to use two auditors, the question arises as to who will monitor the second auditor. Collusion deterrence depends on the probability of detection, so if the second auditor is not monitored he will collude and lose all his effectiveness for the principal. This reasoning leads inevitably to an infinite regress; we need a third auditor to monitor the second, a fourth to monitor the third, and so on.

I will show that it is possible to design a system of rewards and punishments so that the two auditors police each other. Even though double-checks are a good 
idea, they are costly. The cost of sending two auditors may cause such an arrangement to be suboptimal. We ask, then, whether it is possible to deter collusion by sending the second auditor with probability less than one.

I conclude that, under reasonable assumptions on the size of rewards and punishments, the principal can achieve truthful reporting only by 'creating' a new type of auditor. When sending the two auditors sequentially the principal cannot stop collusion if he tells them either always or never whether they are the first or the second auditor. However, by sometimes informing the second auditor of his position and not telling the agent whether the second auditor is informed, he can effectively stop collusion. The intuition behind this result is that the second auditor, when informed about his position, will require a bribe unprofitable for the uninformed agent to pay, given that a bribe has already been paid to the first uninformed auditor. In other words, the second auditor will never collude when he knows his position and when the first auditor does not know his position. ${ }^{1}$ By introducing the imperfect information the principal 'creates' this new type of auditor and is able to deter collusion. Let public Company Accounting Oversight Board(PCAOB) supervise the auditors is like designate another auditor to supervise the first auditor. Although the PCAOB hold higher authority and cannot inspect as careful as the auditor, its role in detecting collusion is the same as a second auditor.

The mechanism I propose is an example of Bayesian Perfect implementation. That is to say, I trim the set of equilibria of the game defined by the principal using the Bayesian Perfect Nash criteria.

There is a variety of settings in the agency literature wherein the principal gains from withholding information from the agent [5]. Our analysis extends this idea to a hierarchical setting where the principal garbles his communication with the auditor as opposed to the agent. In contrast to Maskin and Tirole, our principal does not design a contract that maximizes ex post information asymmetry between him and the agent and preserves his private information. In the framework, the principal has no private information; instead, by creating a hidden randomization-which does not affect the exogenous parameters of the model-the principal creates the source of his private information.

Tirole was the first to study the phenomenon of bribes in a hierarchical contract involving a principal, a auditor and an agent [6]. However, Tirole rules out the possibility of adding a second auditor.

${ }^{1}$ If they both know their position, collusion cannot be prevented.
In Kofman and Lawarrée, they make use of the auditor's prisoner's dilemma to deter the collusion $[7,8]$. Khalil and Lawarrée [7] also use an external signal as a credible auditor to prevent collusion [9]. But all their paper assume that the manager will give in the outcome produced with the principal's assets. They do not consider the real facts that the manager can earn by pushing the market value of the firm as high as possible, as their compensation is proportional to firms' market (or share) value. Criminal investigations proved that on the eve of the crisis, several large firm CEOs, resorted to corrupt auditors to produce false, overly optimistic financial statements, which helped inflate share values. In what appeared to be outrageous conduct, some executives reaped million dollar gains by exercising pending stock-options just before the collapse of the company [10-12]. We will analyze this important element in this paper.

Laffont and Martimort also investigate the simultaneous use of two collusive auditors. They show that information per se introduces increasing returns in the benefits of side-contract. By duplicating auditors, the principal can reduce their information and their discretion, and, therefore, improve expected welfare [13].

Barry analyzes accountant's ethical standards' effects to their audit results [14]. We also consider this element's influence on the auditor's behavior when facing the temptation of collusion. The state owned company dominates the economic development of china. From the data of the Chinese stock market in June 16, 2003, in all public companies almost $48 \%$ is absolutely controlled by the government, while $81 \%$ of all is relatively controlled by the government. This means most of Chinese public company is dominated by the state and the company's major shareholder is the state. While in china it is the state assets management committee which exercises the rights of major shareholder. When supervising the enterprise, deterring the collusion, the charger of this committee gets the benefits not only from confiscating the information rent pocketed by the enterprise manager, but also from gaining the good political achievement by deterring the collusion. We will analyze the charger's function in preventing collusion in the following discuss.

The paper is organized as follows. In Section 2 we model the problem as a game theoretical situation, discuss reasonable assumptions about the magnitude of penalties and rewards, and we present a simple, collusion-proof mechanism. In Section 3 we explore the possibility of sending the second auditor with a probability less than one and show that a simple model yields counter-intuitive results. Section 4 presents a resolution of this problem and restores our initial intui- 
tion. Finally, Section 5 gathers our conclusions.

\section{Description of the Model}

\subsection{The Game Sequence}

We consider a vertical structure represented by a threelayer hierarchy: principal-auditor-agent. The principal owns a productive technology, but lacks the skills or the time necessary to operate it and must hire an agent for that purpose. ${ }^{2}$ The agent is the productive unit. The principal also lacks the knowledge to supervise the agent. He can hire auditors whose only role is to audit the agent. ${ }^{3}$ We assume the audit cost is $c^{a}$ and the principal would like to give reservation wage $w^{a}$ to the auditors, which is equal to the cost the principal spend when he do this work by himself. ${ }^{4}$ All players are risk neutral.

The agent's ability to perform depends on a characteristic unobservable to the principal. This characteristic (or type) is the agent's private information and determines his productivity. We assume that the agent can only be of two types: high productivity or low productivity. To simplify the analysis and gain the intuitional results, we assume the agent's operation cost is the same $c^{m}$ no matter what his type is. The principal pay the agent according to their report, he gives the wage $w^{m}\left(s_{h}\right)$ to those agents who present high productive report and $w^{m}\left(s_{l}\right)$ to those agents who present low productive report. Here $s_{i}$ denote the report presented by the agents, $i \in(l, h), s_{h}$ represent high productive report, ${ }^{s_{l}}$ represent low productive report, obviously $w^{m}\left(s_{h}\right)>w^{m}\left(s_{l}\right)$.In the second-best contract without auditors if the high productive agent report low output he can obtains $\pi\left(s_{l}\right)$, while the low productive agent can obtains $\pi\left(s_{h}\right)$ if he report high output. $^{5}$ (For an underlying structure yielding this result, see $[15,16]$. Now I denote $\eta_{i}$ as the information rent the agent can earn in the end, $i \in(l, h)$. For the high productive agent, $\eta_{h}=\pi\left(s_{l}\right)-w^{m}\left(s_{h}\right)+w^{m}\left(s_{l}\right)$, for the low productive agent,

\footnotetext{
${ }^{2} \mathrm{I}$ do not allow the principal to sell the firm. While in china, it is the state assets management committee supervising the state-owned enterprise. It sends the agent to manage the enterprise. The leader of the state assets management committee plays the role as the principal.

${ }^{3}$ The use of auditor(s) may not be the only way for the principal to achieve better control of his agent. In some cases, it is not even feasible as in the case of relationships between doctors and patients, lawyers and clients, advisors and Ph.D. students. The principal may also duplicate the agents to get more information. This method, however, may be very inefficient. A typical example is the regulation of a private firm (agent) characterized by increasing returns to scale. The existence of competition can reduce the incentive problem, but some of the benefits of scale economies will be wasted. Our model studies the efficiency of using a third party (auditor) to lessen the information asymmetry problem. It is then assumed that other institutional arrangements are not feasible.
}

$$
\begin{aligned}
& \eta_{l}=\pi\left(s_{h}\right)-w^{m}\left(s_{l}\right)+w^{m}\left(s_{h}\right) . \text { Because } \\
& \eta_{h}-\eta_{l}=\pi\left(s_{l}\right)-\pi\left(s_{h}\right)-2 w^{m}\left(s_{h}\right)+2 w^{m}\left(s_{l}\right) \text { and in } \\
& \text { most cases } \pi\left(s_{h}\right)>\pi\left(s_{l}\right),
\end{aligned}
$$$$
\text { So } \pi\left(s_{l}\right)-\pi\left(s_{h}\right)-2 w^{m}\left(s_{h}\right)+2 w^{m}\left(s_{l}\right)<0 \text {, then we }
$$
get $\eta_{h}<\eta_{l} \cdot{ }^{6}$ I assume that the agent has limited liability and the contract must award him a non-negative payoff in any state of the world.

To reduce the informational rents of the agent, the principal can employ a self-interested auditor at cost $w^{a}$. We assume that the auditor cannot buy the right to audit. He can be subject, though, to negative transfers if he is caught lying. The auditor learns the agent's private information without mistakes and obtains verifiable evidence. His report to the principal, however, can differ from his observation. If he can gain by manipulating the report and the agent agrees, he will do so. We require that the agent collaborates in manipulating the information to avoid cases in which the auditor can 'frame' the agent. The auditor can gain by manipulating his reports because the agent can give him a conditional side-transfer (a bribe, $B$ ). The agent may share his rent $\eta_{i}$ to get the auditor to present false information to the principal.

To prevent collusion, the principal could match the agent's bribe with a reward $R$. This solution does not improve the principal's payoff. Since the agent will lose $\eta_{i}$ if reported to the principal, he will be willing to pay up to $\eta_{i}$ to the auditor to present a false report. To discourage the auditor from doing that, the principal will have to match the bribe and pay $\eta_{i}$ to the auditor when his report extracts the agent's rents. This is a 'bounty-hunter' scheme where the auditor obtains all the informational rents from the agent.

Another strategy to prevent collusion is to hire a second auditor at cost $w^{a}$. This auditor is similar to the first. He is self-interested, learns perfectly the agent's private information and obtains verifiable evidence. He can manipulate this evidence with the help of the agent to give the principal a false report. Being the first auditor, he cannot pay for the right to audit but can be subject to negative transfers if caught lying. The way in which an auditor can be caught lying is that the

\footnotetext{
${ }^{4}$ The audit cost is in proportion with the amount of the enterprise's transaction, as the two principal audit the same enterprise, I denote their audit cost is the same $c^{a}$.

${ }^{5}$ When the agent is high productivity, if he disguises to be low productivity, he can only turn in the low output and seize the exceed part. While when the agent is low productivity, if he disguises to be high productivity, he can gain benefits by gaining high income as his stock ownership incentive is proportional to company's market value.

${ }^{6}$ For many real cases, $\pi\left(s_{h}\right)>\pi\left(s_{l}\right)$, we can proof it with the evidence from Enron, Worldcom,etc.
} 
two reports disagree. The truth-teller will have evidence to verify his report while the liar will not. When this is the case, the principal can apply a non-pecuniary punishment $(P)$ on the lying auditor. When two auditors participate in the contract, the reward for the principal is not only from extracting the rents from the agent but also from potentially uncovering the false report of the other auditor. For the leader of state assets management committee, investigating and treating the collusion can provide good achievement in his post. ${ }^{7}$ We are interested in situations where the principal uses the auditors; therefore we will assume that their cost is sufficiently low, i.e. $2 w^{a}<\eta_{i}$.

We assume that the agent has all the bargaining power in his negotiation with the auditors. He is the only one who can commit to a side-transfer so he can make a conditional take-it-or-leave-it offer. He can offer any bribe he wants, but he will never offer bribes that add to more than his rent. (His Nash threat payoff is zero, so he will not go below that.)

We assume that the punishment to the colluding auditors $(P)$ cannot exceed $P . P$ is the modeler's reflection of social practices. We need to determine the minimum value of $P$ which could prevent collusion.

We assume the auditor will condemn himself for collusion as it is against his ethical standards. This make him suffer a effects loss $l$. I also assume that the reward for the auditors $(R)$ is lower than the rent $\eta_{i}-2 l$. If $R$ exceeded $\eta_{i}-2 l$, the agent and the supervisor might collude and share the surplus of the coalition $R-\eta_{i}+2 l .^{8}$ Here I notice the principal provide reward $R\left(s_{i}\right)$ with the report the agent present, $i \in(l, h)$. As we have discussed, when the agent present low productive report, the maximum reward should be bounded above by $R\left(s_{l}\right)=\eta_{h}-2 l$, while when the agent present high report, the maximum reward should be bounded above by $R\left(s_{h}\right)=\eta_{l}-2 l$, obviously we get $R\left(s_{l}\right)<R\left(s_{h}\right)$ with $\eta_{h}<\eta_{l}$. Oth-

\footnotetext{
${ }^{7}$ The For the leaders of state assets management committee, they can share the confiscated $\eta_{i}$ in a proportion $k$. I use $m$ to indicate the collusion deterrence's contribution to the leaders achievement. Then the gains from collusion deterrence for leaders are $k \eta_{i}+m$.

${ }^{8}$ The principal will pay the reward no more than $\eta_{i}$ to the auditor, as being a rational person, he will not pay the reward more than what he can earn. The principal realize he can use the point that the auditor will suffer remorse when colluding with agent, so he can pay no more than $\eta_{i}-2 l$ to prevent collusion. Let's analyze the state-owned enterprise's supervisor's decision in this situation, he can gain $k \eta_{i}+m$ in investigating and treating the collusion and also will not raise $R$ at will to induce the auditor disclose the agent's fraudulent. Since when $R>\eta_{i}$, the auditor will collude with the agent to share the part that $R$ surpass $\eta_{i}$, especially when the $R$ is very large. Then for the principal of the state-owned enterprise, he will also give a reward $R \leq \eta_{i}-2 l$.
}

erwise it can not deter the collusion because when $R\left(s_{l}\right)>R\left(s_{h}\right)$, the agent will collude with the auditor to share the part $R\left(s_{l}\right)$ surpass $\eta_{h}-2 l$ as $\eta_{h}<\eta_{l}$. To satisfy this requirement, the principal will contract with the auditor to give the reward $R\left(s_{\bar{i}}\right)$ in the agent's report. To get more clear results, I introduce $\bar{i} \in(l, h)$, when agent report high outcome, $\bar{i}=h$ and when agent report low outcome, $\bar{i}=l$. It should be emphasized $\bar{i}$ is the opposite of $i$, which means when $i=h, \bar{i}$ will be $l$ and when $i=l, \bar{i}$ will be $h$. To simplify, we set $R_{\bar{i}}=R\left(s_{\bar{i}}\right)$. Then from the discuss above, we get $R_{\bar{i}} \leq \eta_{i}-2 l$. We also assume that the reward is paid only to the auditor uncovering collusion between the agent and the supervisor. Therefore, an auditor reporting detrimental information about the agent does not necessarily collect a reward. We have analyzed a model where this assumption does not hold elsewhere.

Summarizing: the timing of the game is:

1) Nature draws a type for the agent. The agent obtains a rent of $\eta_{i}>0$.

2) The principal sends the two auditors simultaneously under a contractual agreement that specifies transfers as a function of their reports. The transfers would be:

\begin{tabular}{lcc}
\hline & High prod. report & Low prod. report \\
\hline High prod. report & 0,0 & $R_{\bar{\tau}},-P-l$ \\
Low prod. report & $-P-l, R_{\bar{\tau}}$ & 0,0 \\
\hline
\end{tabular}

(If the auditors' reports differ, the principal will reward the truth-telling and punish the liar.)

3) Both auditors observe the agent's type.

4) The agent can commit to side-transfers to the auditors conditional on their reports.

5) Both auditors report simultaneously.

6) Transfers and side-transfers are realized.

\subsection{The Analysis of Prisoner's Dilemma}

When the principal sends both auditors simultaneously, if $\bar{P}>\eta_{i} / 2$, he can make the two auditors play a prisoner's dilemma. Each auditor can choose between reporting truthfully or lying. The payoff matrix is:

\begin{tabular}{lccc}
\hline & & \multicolumn{2}{c}{ Auditor 2} \\
& Report truth & 0,0 & $R_{\bar{i}}, B-P-l$ \\
\multirow{2}{*}{ Auditor 1} & Lie & $B-P-l, R_{\bar{i}}$ & $B-l, B-l$ \\
\hline
\end{tabular}

To guarantee that the outcome (report truth, report 
truth) is a Nash equilibrium, we need $P \geq B-l$. This condition is easily verified since $B \leq \eta_{i} / 2$ (by the agent individual rationality constraint) and since $P$ can be greater than $\eta_{i} / 2 \quad\left(\bar{P} \geq \eta_{i} / 2\right.$ and $\left.P \leq \bar{P}\right)$.

To guarantee that the outcome (lie, lie) is not a Nash equilibrium, we need $R_{\bar{i}}>B-l$. Since $B \leq \eta_{i} / 2$, $R_{\bar{i}}>\eta_{i} / 2$ will do the job while respecting the principal's budget constraint $\left(R_{\bar{i}} \leq \eta_{i}\right)$.

Therefore, if those two conditions are satisfied ( $P>B-l$ and $R_{\bar{i}}>B-l$ ), the principal always gets a truthful report. This mechanism seems to be extremely powerful. The only (mild) assumption we need to make is that the punishment imposed on an auditor who accepts a bribe be slightly higher than the bribe.

If a prisoner's dilemma is so efficient, one might wonder why this type of mechanism is not observed more frequently in the real world. Restrictions on the values of $P$ or $R$ do not seem to be the cause. Rather, the cost of doubling the supervisory function appears to be a more serious problem. ${ }^{9}$ Such an increase in the number of regulatory agencies or Internal Revenue Service (IRS) auditors, for instance, might not be financially feasible. In that case, the interesting question is whether a collusion-free outcome will remain an equilibrium when the principal sends a second auditor with some probability (call it $\gamma$ ) less than one. Intuition suggests that, if $P$ can be increased, $\gamma$ can be decreased proportionally. And, indeed, casual observation of the real world shows that an auditor caught accepting a bribe suffers a punishment much higher than was the bribe itself. The limited financial liability of the auditors can easily be overcome by using nonmonetary punishments, ranging from loss of face to imprisonment.

In the next section we study a game where the auditors are not sent simultaneously to audit the agent. We explore the possibility of sending the second one with a probability less than one when $P$ is allowed to grow.

\section{The Analysis of Bayesian Equilibrium}

Let us call our two potential auditors $A_{1}$ and $A_{2}$. Note that the principal is completely indifferent between sending either auditor in the first place. Therefore, let us say, without loss of generality, that he sends each with a probability $1 / 2$. We also assume that the principal does not tell the auditors their sequence. More generally, we will call $\xi$ the probability of telling the second auditor his position. So, here, we assume that

\footnotetext{
${ }^{9}$ If this game is repeated, collusion is also more likely (see [17]). Also, as in any prisoner's dilemma, communication between the two auditors must be prevented. This assumption seems reasonable when the principal has a very large pool of auditors available (government, large corporation, etc.).
}

$\xi=0$.

At this point, it is useful to recall the timing of our game.

Assume that Nature has drawn a type of agent such that this agent can earn a positive rent $\left(\eta_{i}>0\right)$. The type is the agent's private information. (If Nature draws a type of agent such that $\eta_{i}=0$, the timing is similar, but no bribing occurs.)

(1) The principal randomizes and sends the first auditor who observes $\eta_{i}>0$.

(2) The agent offers a bribe $B_{1}$ to the first auditor. The agent can commit to $B_{1}$. The principal cannot observe $B_{1}$.

(3) (a) If the auditor refuses the bribe, he reports that $\eta_{i}$ is positive. The agent gets no rent. End of the game. (b) If the auditor accepts the bribe, he receives $B_{1}$ and reports $\eta_{i}=0$.

(4) The principal sends the second auditor with probability $\gamma$, which is common knowledge.

(5) The agent offers a bribe $B_{2}$ to the second auditor. The agent can commit to $B_{2}$. The principal cannot observe $B_{2}$.

(6) (a) If the second auditor accepts the bribe, he reports that $\eta_{i}=0$. The two auditors keep their bribes and the agent collects $\eta_{i}$. End of the game. (b) If the second auditor refuses the bribe, he reports $\eta_{i}>0$ and collects $R_{\bar{i}}$. The first auditor keeps his bribe, but is punished with $P$. The agent loses the bribe to the first auditor and does not collect $\eta_{i}$. The principal collects $\eta_{i}$ and pays the reward to the second auditor. End of the game.

The equilibrium concept we will use is the Perfect Bayesian Equilibrium [18]. Loosely speaking, the strategies chosen by each player must be their best response to the other player's strategy, and their posterior beliefs are derived from their prior beliefs using Bayes' Rule. In this game, the agent must choose the amount of the bribes $\left(B_{1} \geq 0\right.$ and $\left.B_{2} \geq 0\right)$ and the auditors must decide whether to accept the bribe. This game is played conditional upon a fixed strategy of the principal. This strategy is characterized by the parameters $\gamma$, $R, P$ and $\xi$. The fixed strategy of the principal should be feasible, i.e. belong to a strategy_set described by means of the following constraints: $R_{\bar{i}} \leq \eta_{i}-2 l, 0 \leq \gamma \leq 1, \quad P \leq \bar{P}, 0 \leq \xi \leq 1$.

When an auditor must decide whether to accept or reject a bribe, it is very important for him to know if he is the first or the second auditor. Suppose, for instance, that he knows that the first auditor has already accepted a bribe. In that case, he would simply compare the bribe offered by the agent with the reward he could get from the principal by denouncing the first auditor. However, if he knows he is the first auditor, his action 
will depend on his beliefs about the likelihood of the second auditor accepting the bribe.

As discussed before, the probability that the principal hire auditor $A_{1}$ is $1 / 2$, auditor $A_{2}$ is hired in a probability $\gamma$ when $A_{1}$ collude with the agent(call $\beta$ the probability that the first auditor colludes), ${ }^{10}$ so the probability that he is chosen is $(\beta \gamma) / 2$. It is obviously the probability been chosen as a auditor is $(1+\beta \gamma) / 2$. According to the Bayesian rule, the auditor can calculate the probability of his sequence,

the probability being $A_{1}$ is

$$
P(1)=\frac{1 / 2}{(1+\beta \gamma) / 2}=\frac{1}{1+\beta \gamma}
$$

the probability being $A_{2}$ is

$$
P(2)=1-P(1)=\frac{\beta \gamma}{1+\beta \gamma}
$$

Then when the auditor refuse bribe, the ECr[Expected Cost(Refuse)] is

$$
E C r=P(1) c^{a}+P(2)\left(c^{a}-R_{\bar{i}}\right)=c^{a}-\frac{R_{\bar{i}} \beta \gamma}{1+\beta \gamma}
$$

It means: if it is auditor $A_{1}$, then his audit cost is $c^{a}$, if it's auditor $A_{2}$, except $c^{a}$, he can possibly get the reward $R_{\bar{i}}$ for disclosing the collusion between former auditor and agent to decrease the real cost.

When the auditor receive the bribe, the ECa [Expected Cost(accept)] is

$$
\begin{aligned}
& E C a=P(1)\left\{c^{a}+l-(1-\gamma) B_{1}\right. \\
& \begin{aligned}
\left.+\gamma\left[-\beta B_{1}+(1-\beta)\left(P-B_{1}\right)\right]\right\}+P(2)\left(c^{a}+l-B_{2}\right) \\
\quad=c^{a}+l-\frac{B_{1}+\beta \gamma B_{2}}{1+\beta \gamma}+\frac{P \gamma(1-\beta)}{1+\beta \gamma}
\end{aligned}
\end{aligned}
$$

Which means when the auditor is $A_{1}$ and receive bribe: 1 ) if $A_{2}$ refuse bribe(the probability is $1-\beta$ ), then $A_{1}$ will be punished with $P$; 2)if $A_{2}$ accept bribe $B_{2}$, the real audit cost of $A_{2}$ will have $B_{2}$ decrease because of the bribe. $\gamma$ is the probability the principal will employ auditor $A_{2}$, the auditor $A_{1}$ will loss $l$ in all this situations. When $E C a>E C r$, the rational auditor will choose to refuse bribe, from Equations (1), (2), I get

$$
R_{\bar{i}} \beta \gamma>\left(B_{1}+\beta \gamma B_{2}\right)-P \gamma(1-\beta)-l(1+\beta) \gamma
$$

Now I restrict the discussion in the pure strategy of $\beta=0$ or $\beta=1$ and the two equilibrium under pure strategy: when $B_{1}=B_{2}$, two auditor get the same bribe, then a pooling equilibrium form; when $B_{1} \neq B_{2}$, a se-

\footnotetext{
${ }^{10}$ Here I denote $A_{1}$ as the first auditor and $A_{2}$ as the second auditor.
}

parating equilibrium will form.

\subsection{The Analysis of Pooling Equilibrium $\left(B_{1}=B_{2}\right)$}

When both auditor think the other will not accept the bribe, that is to say $\beta=0$, the pooling equilibrium will emerge. From Equation (3), we know

$$
B<P \gamma+l \gamma
$$

This indicate when the bribe is fixed, the bigger the probability $\gamma$ sending out auditor $A_{2}$, the litter the punishment $P$ required to deter the pooling equilibrium of the collusion; the stronger the auditor's morality favor, the litter the punishment. $P$ will reach the minimum when the double auditing $(\gamma=1)$ is implemented.

When auditor $A_{1}$ and $A_{2}$ all predicate the other will accept bribe $(\beta=1)$, from Equation (3), we get

$$
B<\frac{\gamma\left(R_{\bar{i}}+2 l\right)}{1+\gamma}
$$

Which means for every auditor, the bribe he would

like to accept is at least $B_{\min }=\frac{\gamma\left(R_{\bar{i}}+2 l\right)}{1+\gamma}$.

To understand it, we take consideration of $\gamma=1$ (when the first auditor report no fraudulent, the principal always send out the second auditor). In this situation, the minimum bribe the auditor will accept is $B=\left(R_{\bar{i}}+2 l\right) / 2$.

It is obviously that the minimum bribe can be satisfied and the condition $\beta=1$ is a better status for the auditor because of $w^{a}<w^{a}+B$. Then can the principal find an effective way to deter the happening of pooling equilibrium of the collusion? We can get the answer from the following proposition.

Proposition 1: when the principal does not tell the auditor his sequence $(\xi=0)$, the pooling equilibrium will appear.

Proof: assuming pooling equilibrium of the collusion can be prevented and $B_{1}=B_{2}=B$. The agent's incentive restriction is $B+B \gamma \leq \eta_{i}$, which means $B \leq \eta_{i} /(1+\gamma)$, the max bribe the agent would like to give is $B_{\max }=\eta_{i} /(1+\gamma)$. While to any auditor, the minimum bribe he would like to accept is $B_{\min }$. When $B_{\max }<B_{\min }$, the pooling equilibrium of the collusion can be deterred. Now

$$
\frac{\gamma\left(R_{\bar{i}}+2 l\right)}{1+\gamma}>\frac{\eta_{i}}{1+\gamma} .
$$

Which means $\eta_{i} /\left(R_{\bar{i}}+2 l\right)<\gamma \leq 1$, it is contrast with the assumption $R_{\bar{i}}+2 l \leq \eta_{i}$. So when $\xi=0$, the pooling equilibrium of the collusion will appear. 


\subsection{The Analysis of Separate Equilibrium $\left(B_{1} \neq B_{2}\right)$}

Proposition 2: when the principal tell the auditor his sequence $(\xi=1)$, the separate equilibrium of the collusion will emerge.

Proof: if the bribe $B_{2}$ provided by agent is higher than the reward $R$ for the auditor, and is large enough to compensate his morality self-accusation, then the rational auditor $A_{2}$ will collude with the agent; now, if $B_{1} \geq l, B_{2} \geq R_{\bar{i}}+l$, the best strategy for auditor $A_{1}$ is to collude with agent in this game. The manager will bribe the first auditor under the restriction $B_{1}+\gamma B_{2} \leq \eta_{i}$, he will bribe the second auditor under the restrition $B_{2} \leq \eta_{i}-B_{1}$. Whether to bribe the second auditor determine the success of the collusion. To deter the collusion, we need $R_{\bar{i}}>\eta_{i}$, but as is known to all, the principal won't pay such a high reward, so the separate equilibrium of the collusion will not form.

The proposition 1 and 2 demonstrate no matter how high the punishment is, the principal can not prevent the happening of collusion. The reason is when the collusion equilibrium form, the auditor does not fear to be punished because they will never be caught actually. And we can see the collusion can not be deterred whether $\xi=0$ or $\xi=1$. If we let the principal have the ability to inform the second auditor about his sequence with probability $\xi \in(0,1)$, can we deter the collusion by introducing the asymmetric information? The following solution methods can give an answer to this problem.

\section{The Solution}

Proposition 3: through choosing the probability $\xi \in(0,1)$ to tell the second auditor his sequence (no matter whether tell the first auditor his sequence or not), the principal can deter collusion equilibrium:

1) when $R_{\bar{i}}>\frac{\eta_{i}}{1+(1-\xi) \gamma}-l$, the separate equilibrium of the collusion can be deterred;

2) when

$R_{\bar{i}}>\max \left\{\frac{\eta_{i}}{1+\gamma}, \frac{\eta_{i}-\left(\eta_{i}+P\right) \xi \gamma-l[1+\gamma(1-\xi)]}{\gamma(1-\xi)}\right\} \quad$ and $P>\max \left\{\frac{B-l}{\gamma}, \frac{(B-l)[1+\gamma(1-\xi)]}{\gamma \xi}-\frac{R_{\bar{I}}(1-\xi)}{\xi}\right\}$, the pooling equilibrium of the collusion can be prevented.

Proof 1: under separate equilibrium of the collusion, the rational restriction of the auditor is $B_{1} \geq l, B_{2}$ $\geq R_{\bar{i}}+l$; the incentive restriction is :

1) the agent don't have any incentive to tell the first auditor that he is the second if $B_{1}+\gamma B_{2} \leq B_{2}+\gamma B_{2}$, which is obviously equivalent to $B_{2} \geq B_{1}$

2 ) the agent has no incentive to tell the second auditor that he is the first if $B_{1}+B_{2} \leq B_{1}+(1-\xi) B_{1}+\xi \eta_{i}$, which is equivalent to $B_{2} \leq(1-\xi) B_{1}+\xi \eta_{i}$, as

$B_{2} \geq R_{\bar{i}}+l$, then we get $B_{1} \geq \frac{R_{\bar{i}}+l-\xi \eta_{i}}{1-\xi}$. In addition $\gamma B_{2} \geq \gamma\left(R_{\bar{i}}+l\right), \eta_{i} \geq B_{1}+\gamma B_{2}$.

We finally get $R_{\bar{i}} \leq \frac{\eta_{i}}{1+(1-\xi) \gamma}-l$, so when $R_{\bar{i}}>\frac{\eta_{i}}{1+(1-\xi) \gamma}-l$, the separate equilibrium of the collusion will be prevented.

Proof 2: under pooling equilibrium, $B_{1}=B_{2}$.

1) When $B_{1}=B_{2}=R$, the incentive restriction of the agent is $B_{1}+\gamma B_{2} \leq \eta_{i}$, that is $R_{\bar{i}} \leq \frac{\eta_{i}}{1+\gamma}$, so when $R_{\bar{i}}>\frac{\eta_{i}}{1+\gamma}$, then pooling equilibrium of the collusion can be prevented;

2) when $B_{1}=B_{2}=B<R_{\bar{i}}$, if

$R_{\bar{i}}>\frac{\eta_{i}-\left(\eta_{i}+P\right) \xi \gamma-l[1+\gamma(1-\xi)]}{\gamma(1-\xi)}$ and

$P>\max \left\{\frac{B-l}{\gamma}, \frac{(B-l)[1+\gamma(1-\xi)]}{\gamma \xi}-\frac{R_{\bar{i}}(1-\xi)}{\xi}\right\}$, we

can prevent the pooling equilibrium of the collusion, the proof can be seen in appendix.

So when

$R_{\bar{i}}>\max \left\{\frac{\eta_{i}}{1+\gamma}, \frac{\eta_{i}-\left(\eta_{i}+P\right) \xi \gamma-l[1+\gamma(1-\xi)]}{\gamma(1-\xi)}\right\} \quad$ and $P>\max \left\{\frac{B-l}{\gamma}, \frac{(B-l)[1+\gamma(1-\xi)]}{\gamma \xi}-\frac{R_{\bar{i}}(1-\xi)}{\xi}\right\}$, we can prevent pooling equilibrium of collusion.

\section{Conclusions}

This paper analyzes the audit collusion reason and provides a collusion-proof mechanism with double auditing. We have the following conclusions:

1) When expanding the game model from single period into multi-period, we can make two auditors supervise each other well in an appropriate incentive mechanism and they will choose not to collude with the agent in the end because the multi-period game can sequentially weaken their collusion favor. Then we can regress the double auditing system into the single auditing system by making the agent form a predication 
that another auditor will go to audit, while only one auditor take action in fact. It will not only lower the social supervising cost on the auditor, but also decrease the auditing cost of the principal.

2) Now, to prevent audit collusion, we need strengthen and broaden the supervision on auditor, enhance the lawful punishment and perfect the incentive mechanism for the auditor. The auditor's morality favor can decrease the punishment and reward required to prevent collusion, while increase the bribe cost for the agents.

3) An important restrictive condition is $R_{\bar{i}} \leq \eta_{i}-2 l$. Without this constraint, our deduction in this paper will not be established, because high reward will induce the agent and auditor to collude and share the part $R_{\bar{i}}$ surpass $\eta_{i}-2 l$, while low reward can not give the auditor enough incentive to resist temptation. Through observing the agent's report $s_{i}$ and making use of the experiments, the principal can satisfied this requirement and provide effective $R_{\bar{i}}$ to deter collusion.

4) When the charger of state-owned management committee works as the principal of state-owned enterprise, although he is not the real owner of the enterprise, he can play the same effects in deterring collusion as the real owner with the incentive that income depending on confiscating information rent and achievement depending on collusion deterrence. So our research provide theory support for the publicly audit bidding and random double auditing, which is widely used in china now. PCAOB set up in January, 2003 is also a excellent practice of our theory. It irregularly inspect the auditor work to detect whether there exist fraudulent behavior. This action is the same as designating a second auditor in a probability and can effectively decrease the auditor's inclination to provide fake reports.

\section{Acknowledgements}

This paper is sponsored by the Chinese national science foundation project (No: 70772039).

\section{REFERENCES}

[1] C. Cullinan, "Enron as a Symptom of Audit Process Breakdown: Can the Sarbanes-Oxley Act Cure the Disease?” Critical Perspectives on Accounting, Vol. 15, No. 6-7, 2004, pp. 853-864.

[2] S. Baiman, J. Evans and J. Noel, "Optimal Contract with a Utility Maximizing Auditor,” Journal of Accounting Research, Vol. 25, No. 2, 1987, pp. 217-244.

[3] S. Baiman, J. H. Evans III and N. J. Nagarajan, "Collusion in Auditing," Journal of Accounting Research, Vol.
29, No. 1, 1991, pp. 1-18.

[4] A. Finkle and D. Shin, "Conducting Inaccurate Audits to Commit to the Audit Policy," International Journal of Industrial Organization, Vol. 25, No. 2, 2007, pp. 379-389.

[5] E. Maskin and J. Tirole, “The Principal-Agent Relationship with an Informed Principal: The Case of Private Values,” Econometrica, Vol. 58, No. 2, 1990, pp. 379409.

[6] J. Tirole, "Hierarchies and Bureaucracies: On the Role of Collusion in Organizations," Journal of Law, Economics and Organizations, Vol. 2, No. 2, 1986, pp. 181-214.

[7] F. Kofman and J. Lawarrée, “A Prisoner's Dilemma Model of Collusion Deterrence,” Journal of Public Economics, Vol. 59, No. 1, 1996, pp. 117-136.

[8] F. Kofman and J. Lawarrée, "On the Optimality of Allowing Collusion,” Journal of Public Economics, Vol. 61, No. 2, 1996, pp. 383-407.

[9] F. Kofman and J. Lawarrée, "Collusion in Hierarchical Agency,” Econometrica, Vol. 61, No. 3, 1993, pp. 629656.

[10] B. Lev, “Corporate Earnings: Facts and Fiction,” Journal of Economic Perspectives, Vol. 17, No. 2, 2003, pp. 2750 .

[11] A. Sheleifer, "Does Competition Destroy Ethical Behavior?" American Economic Review, AEA Papers and Proceedings, Vol. 94, No. 2, 2004, pp. 414-418.

[12] B. J. Hall, "Six Challenges in Designing Equity-based Pay,” In: D. H. Chew Jr. and S. L. Gillan, Eds., Corporate Governance at the Crossroads, McGraw-Hill, New York, 2005, pp. 268-280.

[13] J.-J. Laffont and D. Martimort, "Duplication of Regulators against Collusive Behavior,” Mimeo, IDEI, Toulouse, 1994.

[14] B. E. Cushing, "Economic Analysis of Accountants' Ethical Standards: The Case of Audit Opinion Shopping," Journal of Accounting and Public Policy, Vol. 18, No. 3, 1999, pp. 339-363.

[15] D. Baron and R. Myerson, "Regulating a Monopolist with Unknown Costs,” Econometrica, Vol. 50, No. 4, 1982, pp. 911-930.

[16] J. -J. Laffont and J. Tirole, "Using Cost Observations to Regulate Firms,” Journal of Political Economy, Vol. 94, No. 3, 1986, pp. 614-641.

[17] D. Kreps, P. Milgrom, J. Roberts and R. Wilson, "Repeated Prisoner's Dilemma,” Journal of Economic Theory, Vol. 27, No. 2, 1982, pp. 245-252.

[18] D. Fudenberg and J. Tirole, "Perfect Bayesian Equilibrium and Sequential Equilibrium," Journal of Economic Theory, Vol. 53, No. 2, 1991, pp. 236-260. 


\section{Appendix:}

\section{Proof of proposition 3's (2)}

We name "the auditor being told his order" as event $S$, "not being told" as event NS. As discussed before, the probability the designated auditor's order being $A_{1}$ is $P(1)=\frac{1}{1+\beta \gamma}$, the probability being $A_{2}$ is $P(2)=\frac{\beta \gamma}{1+\beta \gamma} \cdot P\left(A_{1} \mid N S\right)$ and $P\left(A_{2} \mid N S\right)$ denote the conditional probability that auditor $A_{1}$ and $A_{2}$ not being told their order, by Bayesian rule we can calculate

$$
\begin{gathered}
P\left(A_{1} \mid N S\right)=\frac{P\left(A_{1} \times N S\right)}{P(N S)}=\frac{P(1)}{P(1)+P(2)(1-\xi)} \\
=\frac{1}{1+\beta \gamma(1-\xi)}, \\
P\left(A_{2} \mid N S\right)=1-P\left(A_{1} \mid N S\right)=\frac{\beta \gamma(1-\xi)}{1+\beta \gamma(1-\xi)} .
\end{gathered}
$$

When the auditor refuses the bribe, his expected audit cost is

$$
\begin{aligned}
E C r & =P\left(A_{1} \mid N S\right) C_{L}+P\left(A_{2} \mid N S\right)\left(C_{L}-R_{\bar{i}}\right) \\
& =C_{L}-\frac{R_{\bar{i}} \beta \gamma(1-\xi)}{1+\beta \gamma(1-\xi)}
\end{aligned}
$$

When the auditor accepts the bribe, his expected audit cost is

$$
\begin{aligned}
E C a & =P\left(A_{1} \mid N S\right)\left\{C_{L}+l-(1-\gamma) B\right. \\
& +\gamma(1-\xi)[-\beta B+(1-\beta)(P-B)] \\
& +\gamma \xi(P-B)\}+P\left(A_{2} \mid N S\right)\left(C_{L}+l-B\right)
\end{aligned}
$$

According to Equation (2), the above equation considers the situation that the principal will not tell the auditor his order. Because $B_{1}=B_{2}=B<R_{\bar{i}}$, the auditor will not collude with agent, taking the $P\left(A_{1} \mid N S\right)$ and $P\left(A_{2} \mid N S\right)$ into the above equation, we get

$$
E C a=C_{L}+l-B+\frac{\gamma P[1-\beta(1-\xi)]}{1+\gamma \beta(1-\xi)}
$$

If the untold auditor will not collude with agent $(\beta=0)$, it requires $\left.E C a\right|_{\beta=0}>\left.E C r\right|_{\beta=0}$ to prevent collusion, we can get $P>\frac{B-l}{\gamma}$; if the untold auditor collude with agent $(\beta=1)$, it requires $\left.E C a\right|_{\beta=1}>\left.E C r\right|_{\beta=1}$ to prevent collusion, we can get

$$
\gamma(1-\xi) R_{\bar{i}} \leq(B-l)[1+\gamma(1-\xi)]-P \gamma \xi
$$

After rearrangement, we get

$$
P \leq \frac{(B-l)[1+\gamma(1-\xi)]}{\gamma \xi}-\frac{R_{\bar{i}}(1-\xi)}{\xi} .
$$

So we need $P>\frac{(B-l)[1+\gamma(1-\xi)]}{\gamma \xi}-\frac{R_{\bar{i}}(1-\xi)}{\xi}$ to prevent the uninformed auditor to collude with manager. Then

When

$$
P>\max \left\{\frac{B-l}{\gamma}, \frac{(B-l)[1+\gamma(1-\xi)]}{\gamma \xi}-\frac{R_{\bar{i}}(1-\xi)}{\xi}\right\},
$$

the collusion between auditor and agent can be prevented.

From Equation (9) we know the minimum accepted bribe that auditor will collude with agent is

$$
B_{\min }=\frac{\gamma(1-\xi) R_{\bar{i}}+P \gamma \xi}{1+\gamma(1-\xi)}+l .
$$

When the auditor $A_{2}$ is told his order( the probability is $\gamma \xi$ ), from condition $B_{2}<R_{\bar{i}}+l$, we know he will not choose to collude with the agent, $A_{1}$ will be punished with $P$, the agent will possibly loss information rent, the new personally rational restriction of the agent is

$$
B[1+\gamma(1-\xi)] \leq \eta_{i}(1-\gamma \xi) .
$$

From this we know the max bribe the agent would like to pay is

$$
B_{\max }=\frac{\eta_{i}(1-\gamma \xi)}{1+\gamma(1-\xi)} .
$$

While the condition to prevent the untold auditor to collude with the agent is $B_{\max }<B_{\min }$, put it into $B_{\max }$ and $B_{\min }$, through rearrange, we get

$$
R_{\bar{i}}>\frac{\eta_{i}-\left(\eta_{i}+P\right) \varepsilon \gamma-l[1+\gamma(1-\varepsilon)]}{\gamma(1-\varepsilon)}
$$

